\title{
3D PRINTING: MODERN MEDICATION MANUFACTURE
}

\section{PAUL S ${ }^{1}$, SRINIVAS L ${ }^{1^{*}}$, PAUL $T^{2}$}

1: GITAM Institute of Pharmacy, GITAM Deemed to be University, Visakhapatnam, India

2: GITAM School of Architecture, GITAM Deemed to be University, Visakhapatnam, India

*Corresponding Author: Dr. L Srinivas; E Mail: slankala@gitam.edu

Received $6^{\text {th }}$ March 2021; Revised $5^{\text {th }}$ April 2021; Accepted $5^{\text {th }}$ May 2021; Available online $1^{\text {st }}$ Jan. 222

\section{https://doi.org/10.31032/IJBPAS/2022/11.1.5806}

\begin{abstract}
$3 \mathrm{D}$ printing is the key for future advancement in pharmaceutical field and precise manufacturing of personalized dosage forms, implantable medical devices. It is a process where objects are manufactured by fusion or deposition of materials in successive layers under computer control. Since 1984 when 3D printing came to existence it has evolved itself and found its place in many sectors including medicine, architecture and recently in pharmaceutical manufacturing. After the approval of the first 3D printed antiepileptic drug by USFDA, it is now finding its place in establishments of personalized medicines. Personalization of medicine provides a wide range of benefit for the patients who need to take medications having narrow therapeutic indices or having a higher predilection to be influenced by genetic polymorphism.3Dprinting offers new opportunities for improving safety, efficiency and convenience of medicines. When seen from an industrial point of view 3D printing has increased productivity, its cost effective and it enhanced collaboration. The review highlights the different important 3D printing processes and the mechanism by which it works, the advantages and disadvantages of each process. It is concluded that $3 \mathrm{D}$ printing is the footprint for the manufacturing of personalized dosage forms and on demand fabrication of pharmaceutical products in critical situation may be an easy task in the future.
\end{abstract}

Keywords: 3D printing technologies, personalized medications, fused deposition modelling, laser based printing technology, inkjet printing system 


\section{INTRODUCTION}

The evolution of printing technologies has resulted in three dimensional printing of objects where a depositing or binding material is deposited layer by layer onto a substrate [1]' The traditional "one-size-fitsall" concept of treatment is becoming a thing of past and getting replaced with new therapies which are personalized to an individual. Thus we are shifting towards the personalized medication from the traditional therapy, as according to National Health Service (NHS) report the traditional treatment pathway is ineffective for $70 \%$ of patients [2]. 3D printing became a major disruptive technology in pharmaceutical field with the innovative production of bespoke objects of virtually any shape and size and of complex geometries.

For the design and controlling of fabrication process, 3D printing uses computer aided drafting technology and programming. It utilizes a scanner that translate geometric features of a 3D object in digital data, a software for processing the digital data received from the scanner and a printer that manufacture desired object using a specific technology [3].

With the introduction of 3D printing, manufacturing of certain oral dosage forms and medical devices has been made possible. It has also gained importance in the drug development process starting from preclinical to clinical stages and to frontline medical care [4]. 3D printing has a lot of advantage to state a few are the ability to accurately control the spatial distribution of API within the dosage form, high production rate, reduction in material wastage thus cost effective and manufacturing of narrow therapeutic index (TI) drugs and manufacturing of novel drug delivery systems [5-8].

The present paper trying to describe about the 3D printing technologies, products being manufactured by this processes, advantages and disadvantages of this technologies.

\section{D PRINTING TECHNOLOGIES:}

For the fabrication of pharmaceutical products, various printing technologies have been used in the past few years $[9,10$, 11]. The printing technologies are extensively used in drug product research and development. With the introduction of 3D printing in dosage form design, leads to fabrication of personalized, multifunctional and novel drug products.

The three most advanced printing technologies widely used are:

- Printing based inkjet system

- Nozzle-based deposition system

- Laser-based writing system.

\section{PRINTING BASED INKJET SYSTEM:}

The technique where liquid droplets are placed onto a substrate in an organized 
manner using a computer aided pattern generating device is basically known as Inkjet based printing system. Lord Rayleigh's instability theory of 1878 is the fundamental or basics of inkjet printing which gives the explanation of breaking of liquid stream or jet into droplets [12]. This theory gives the two broad types of inkjet printing: a) continuous inkjet printing and b) drop on demand (DOD) printing. With these technologies different types of highly porous objects are manufactured.

a) continuous inkjet printing: It uses pressurized flow to generate continuous column of droplets $(50-80 \mu \mathrm{m})$ which gets charged up during its exit from the nozzle and with the help of electrostatic plates it is directed to towards the substrate and the waste are recirculated. The schematic diagram is illustrated in Figure 1.

Advantages: free from nozzle clogging problems, output faster.

Disadvantages: due to recirculation a lot of ink are wasted

b) Drop on Demand printing: it is considered as more accurate and less wateful and droplets size of $(10-50 \mu \mathrm{m})$ are produced at a very high speed but as of required. It is broadly classified into two categories:

i) Drop-on-Drop (DOD) deposition: If the binding material is itself the droplets i.e the "printable fluid" and the binding structure are same material then the system is called
Drop-on-Drop (DOD) deposition [13]. The mechanism of this system is that the droplets after ejecting from the nozzles are subjected to some form of thermal stimulus that leads to evaporation of the solvent and thus solidifying and acts as a support for the next drop to be jetted [14]. The physical properties of the ink plays an important role in controlling of the droplet size for instance the surface tension which is responsible for spherical liquid drops emerging from the nozzle and it should be within $(-30-70 \mathrm{mN} / \mathrm{m})$ [15], the solubility of the incorporated materials and the vapor pressure of the system is highly impacted by the type of solvent, use of atleast one non-volatile solvent to prevent clogging of nozzle [16] and the optimal viscosity of the liquids. The schematic diagram is illustrated in Figure 2

ADVANTAGE: Objects printed by this system are of very high resolutions three dimensional structures.

DISADVANTAGE: limited availability of volatile solvents which should dissolve both the drug and binding material.

The absence of solid substrate leads to nozzle clogging and fluid leakage if the viscosity of the printable liquid is not optimized.

ii) Drop-on-Solid (DOS) deposition: when the droplets (binder ink) are deposited onto solid substrate(powder) to form a solid free form structure in a layer wise manner is 
termed as Drop-on-Solid (DOS) deposition.

The binder ink helps the powder particles to adhere or solidify [8]. The active pharmaceutical ingredients or the drugs can either be in the liquid droplets or mixed in the powder bed. In this system the printhead which sprays the droplets (binder formulation) moves in longitudinal and transverse axis and then the powder bed and part being fabricated are lowered paving a space for new layers to be formed. The powder bed is replenished with powder with the help of levelling roller and these steps continues until the object is fully developed. The durability of the printed object is obtained through evaporation of volatile solvent by thermal sintering [17]. The powder topology and reactivity of binder solution and powder materials are the two powder characteristics which influences these techniques. The interaction between the binder ink and powder in this process is similar to the traditional method of wet granulation [18]. The schematic diagram is illustrated in Figure 3.

ADVANTAGE: average resolution of printed objects, materials used (powders and binder solutions) are already used in the manufacturing of solid oral dosage form thus making it easier for transition from traditional manufacturing methods to $3 \mathrm{D}$ printing.

DISADVANTAGE: particle size of the powder binding material is critical.
The two most common types of actuation with Drop-on-Demand printing system are:

- Thermal print-head

- Piezoelectric print-head.

Thermal print heads use resisters which upon getting electric pulses rises the temperature up to $300^{\circ} \mathrm{C}$ and forms vapor bubble in the ink chamber. The bubble thus formed expands and imparts the energy required for ejecting droplets for printing. Mostly water is used as solvent because of the high temperature generation in the system [19].

Piezoelectric print-head uses a piezoelectric element like crystal or ceramic which on application of voltage shows deformation in shape that creates a pressure pulse to eject the ink out [20]. Piezoelectric print heads show certain advantages over thermal print heads in that substances are not exposed to high temperature and thus prevents degradation of thermoliable drugs and thermal print head are limited only to volatile solvents while piezoelectric print heads utilizes wide range of inks. The schematic diagrams for the print heads are depicted in Figure 4

\section{NOZZLE BASED DEPOSITION SYSTEM:}

The process where the binder solution is mixed with the solid components of system before 3D printing involves the nozzle based deposition system [21]. It is 
computer control manufacturing method that deposits ink directly from nozzle tip layer by layer to create $3 \mathrm{D}$ objects. These system needs to liquefy the materials by a heating/melting step for extruding through the nozzles of the printer. This system is usually divided into two process a) freemelting [pressure assisted microsyringes (PAM) and b) melting material (fused deposition modelling).

\section{a) Pressure-Assisted Microsyringes} (PAM):

The method of extruding semi-solid materials with the help of pressured air piston dispenser (3-5 bars) is called Pressure-Assisted Microsyringes (PAM). With the help of light exposure or drying the extruded materials needs to be solidify. Operation done at room temperature in a continuous flow pattern [22]. To obtain reproducible drug delivery system the major parameter to consider is the rheological properties of the extruding semi-solid materials.

ADVANTAGE: performed at room temperature, best suited for thermolabile drugs, high drug loading

DISADVANTAGE: drying steps are mandatory otherwise high risk of deformation or excessive droplet shrinkage, high chance of nozzle clogging, low resolution.

b) Fused deposition modelling (FDM): The method where thermoplastic materials are used as a starting materials which are drawn by gear system into printheads where it is heated up by heating elements/ liquiefiers into molten state for easy extrusion of the semi solid materials from the nozzle tip onto a build plate is called fused deposition modelling (FDM). The 3D structures can be obtained by the movement of the printhead in $\mathrm{x}$ and $\mathrm{y}$ axis and the platform can move vertically in $\mathrm{z}$ axis. It is deposited in layer by layer fashion which needs to be fused to get the structure [23]. Materials to be extruded needs to be analyzed prior to extrusion for the rheological properties and other parameters like infill density, extruder speed, both nozzle and build plate temperature, nozzle diameter [24]. The schematic diagram is depicted in Figure 5.

ADVANTAGE: it is inexpensive and readily available, novel technique for development of personalized dosage forms (controlled and modified release profiles), designing of gadgets with complicated inner geometries

DISADVANTAGE: degradation of thermolabile substances, a limited number of low-dose thermostable API and biodegradable thermoplastic polymers can be utilized in this technique which limits its applicability in terms of flexibility.

\section{LASER -BASED WRITING SYSTEM:}

It is based on the principle that radiation helps in photochemical reaction where 
polymerization of photo-polymerizable materials takes place and thus forming the 3D objects. It is broadly of two types: a) Stereolithography b) Selective Laser Sintering.

a) STEREOLITHOGRAPHY: It is a computer control method where laser beams are projected towards the photo polymerizable resins/polymers which results in the solidification of the resin. At fixed interval when the resin is solidified to certain extent the platform is lowered along the $\mathrm{z}$ axis and the solidified layer is recoated with the resin and the process continues layer-by-layer until the desired 3D structure obtained [25]. The schematic diagram is depicted in Figure 6.

ADVANTAGES: high level of accuracy and resolutions, desired release pattern of customized drug delivery system obtained, implantable devices of desired shape is obtained and most important application in making of micro-needles.

DISADVANTAGES: availability of biocompatible photopolymerizable polymers are limited, low drug loading, carcinogenic and lot of resins wasted

b) SELECTIVE

LASER

SINTERING: It utilizes a digital monitoring device that directs the laser to draw a specific pattern on the powder bed. After the layer is sintered, a fresh layer is distributed onto the top of the formed layer and the process continues until the desired
3D structure obtained. The schemactic diagram is depicted in Figure 7

ADVANTAGES: High accuracy, complex geometries medical devices can be manufactured, support is not required.

DISADVANTAGES: expensive, lots of waste produced, porous and brittle.

\section{APPLICATION OF 3D PRINTING:}

The benefits of application of 3D printing in pharmaceutical industries are:

i. Medicines are produced at less cost since conventional methods uses lots of processes such as mixing, dry or wet granulations etc thus it increases cost efficiency.

ii. 3D printing technology is faster since multiple steps involved in conventional methods are eliminated thus it enhance productivity.

iii. High resolution, accuracy and reliability products can be obtained from 3D printing technologies.

iv. High drug loading capabilities as compared to conventional methods.

v. Active Pharmaceutical Ingredients which are difficult to formulate like poor water solubility and narrow therapeutic windows drugs can be designed into suitable drug delivery systems.

vi. Patient compliance is increased for those who face difficulties in 
swallowing thus formulation easy disintegrating formulations.

vii. $3 \mathrm{D}$ printing technology helps in exploring 'on-demand pharmacy'.

Some of the drugs which are formulated by the application of inkjet printing are shown
Some of the dosage forms prepared using extrusion based printing (FDM) are shown in Table 2.

Some of the dosage form prepared by laser based writing system (SLA) are shown in

Table 3.

\section{in Table 1.}

Table 1: Application of inkjet printing in formulation of dosage form

\begin{tabular}{|c|c|c|c|c|}
\hline S. No & Drug & Dosage form & Application & Reference \\
\hline 1 & Felodipine & Microdots & Antihypertensive & 26 \\
\hline 2 & $\begin{array}{c}\text { Polyvinyl pyrrolidone } \\
\text { (PVP) }\end{array}$ & Microdots & Excipients & 26 \\
\hline 3 & Insulin & Microneedle & Antihyperglycemia & 27 \\
\hline 4 & $\begin{array}{l}\text { 5-Fluorouracil, curcumin } \\
\text { and } \\
\text { cisplatin }\end{array}$ & Microneedle & Anticancer agents & 28 \\
\hline 5 & Paclitaxel & Microparticles & Anticancer agents & 29 \\
\hline 6 & $\begin{array}{l}\text { Fluorescein 5- } \\
\text { isothiocyanate }\end{array}$ & Microparticles & Fluorescence & 29 \\
\hline 7 & Loperamide & Tablets or capsules & Inflammatory bowel disease. & 30 \\
\hline 8 & Caffeine & Tablets or capsules & CNS stimulant & 30 \\
\hline 9 & Paracetamol & Tablets & Analgesics & 31 \\
\hline 10 & Atenolol & Tablets, sprays & Antihypertensive & 32 \\
\hline 11 & Influenza vaccine & Microneedles & Against influenza viruses & 33 \\
\hline 12 & $\begin{array}{c}\text { Voriconazole and } \\
\text { Itraconazole }\end{array}$ & Microneedles & Antifungal agent & 34 \\
\hline 13 & Piroxicam & Capsules & $\begin{array}{l}\text { Nonsteroidal anti- } \\
\text { inflammatory }\end{array}$ & 35 \\
\hline 14 & $\begin{array}{l}\text { Lysozyme and } \\
\text { Ribonuclease-A }\end{array}$ & Films & Antibacterial and Antiviral & 36 \\
\hline 15 & Erythropoietin & $\begin{array}{l}\text { Uncoated rubber } \\
\text { stopper } \\
\text { Syringes }\end{array}$ & Anemia & 37 \\
\hline 16 & Rifampicin & $\begin{array}{c}\text { Implant, } \\
\text { Nanoparticles }\end{array}$ & Antibiotic & 38 \\
\hline 17 & Levofloxacin & Implant & Antibiotic & 39 \\
\hline 18 & Folic Acid & Nanosuspension & Anemia & 40 \\
\hline 19 & Nitroglycerin & Injection & Angina & 41 \\
\hline 20 & Fenofibrate & Tablets & $\begin{array}{c}\text { Anti Hypertriglyceridemia } \\
\text { and Anti } \\
\text { Hypercholesterolemia }\end{array}$ & 42 \\
\hline 21 & Rapamycin & Tablet & Immunosuppressant & 42 \\
\hline 22 & Ketoprofen & Tablet & $\begin{array}{l}\text { Nonsteroidal anti- } \\
\text { inflammatory }\end{array}$ & 43 \\
\hline 23 & Rasagiline mesylate & Oral dosage & Antiparkinson agent & 44 \\
\hline
\end{tabular}


Table 2: Application of extrusion printing (FDM) in preparation of dosage form

\begin{tabular}{|c|c|c|c|c|}
\hline S. No, & Drug name & Dosage Form & Use & Reference \\
\hline 1 & Domperidone & Tablet & Nausea, vomiting & 45 \\
\hline 2 & Ibuprofen & Tablet & NSAID & 46 \\
\hline 3 & Aminosalicylate & Tablet & Antibiotic & 47 \\
\hline 4 & Metformin, Glimepiride & Tablet & Antidiabetic & 48 \\
\hline 5 & Disopyramide & Tablet & Antiarrhythmic & 49 \\
\hline 6 & Theophylline & Tablet, Capsule & Lung diseases & 49 \\
\hline 7 & Paracetamol & Tablet & Antipyretic & 50 \\
\hline 8 & Budesonide & Controlled release tablet & Ulcerative colitis & 51 \\
\hline 9 & Diclofenac sodium & Tablet & NSAID & 51 \\
\hline 10 & Prednisolone & Extendedrelease tablet & Immunosuppressant & 52 \\
\hline 11 & Enalapril maleate & Tablet & Antihypertensive & 53 \\
\hline 12 & Hydrochlorothiazide & Tablet & Diuretic & 53 \\
\hline 13 & Acetaminophen & $\begin{array}{c}\text { Oral pulsatile capsule, } \\
\text { Tablet MR }\end{array}$ & Antipyretic & 54 \\
\hline 14 & Captopril & Intermediate release tablets & Hypertension, CHF & 54 \\
\hline 15 & Budesonide & Capsule & Ulcerative colitis & 54 \\
\hline 16 & Nitrofurantoin & Catheter, Implant & Urinary tract infections & 55 \\
\hline 17 & Hydroxyapatite & Implant & Carrier & 55 \\
\hline 18 & Dye & Implant CR & Excipients & 56 \\
\hline 19 & Gentamicin & General Device & Antibiotic and Anticancer & 57 \\
\hline 20 & $\begin{array}{c}\text { sulphate,Methotrexate } \\
\text { Furosemide }\end{array}$ & Capsules IR, MR & Congestive heart failure & 58 \\
\hline 21 & Pravastatin & Tablet (IR, SR) & Lower "bad" cholesterol & 50 \\
\hline 22 & Atenolol, Ramipril & Tablet (IR, SR) & Anti -hypertensive & 59 \\
\hline 23 & Aspirin & Tablet (IR, SR) & $\begin{array}{c}\text { Nonsteroidalanti-inflammatory } \\
\text { drug }\end{array}$ & 59 \\
\hline 24 & Hydrochlorothiazide & Tablet (IR, SR) & Anti-hypotensive & 59 \\
\hline 25 & Fluorescein & Tablet & Corneal ulcers and Herpetic & 60 \\
\hline 26 & $\begin{array}{l}\text { 5-aminosalicylic acid and } \\
\text { 4-aminosalicylic acid }\end{array}$ & Tablet (MR) & Antibiotic & 47 \\
\hline 27 & In domethacin & T-shaped (IU, SC rods) & Nonsteroidal anti-inflammatory & 61 \\
\hline 28 & 5- Aminosalicylic acid & Tablets (IR) & Antibiotic & 62 \\
\hline 29 & Captopril & Tablets (IR) & Anti-hypertensive & 62 \\
\hline 30 & Prednisolone & Tablets (IR) & Immunosuppressive drug & 62 \\
\hline
\end{tabular}

Table 3: Dosage forms prepared by laser based writing system (SLA)

\begin{tabular}{|c|c|c|c|c|}
\hline S. No. & Drug name & Dosage form & Use & Reference \\
\hline 1 & Paracetamol & $\begin{array}{l}\text { Oral modified } \\
\text { release tablets }\end{array}$ & Antipyretic & 63 \\
\hline 2 & $\begin{array}{c}\text { 4-Aminosalicylic } \\
\text { acid } \\
\text { Salicylic acid }\end{array}$ & $\begin{array}{l}\text { Oral modified } \\
\text { release tablets } \\
\text { Anti-acne patch }\end{array}$ & Antibiotic & 63 \\
\hline
\end{tabular}




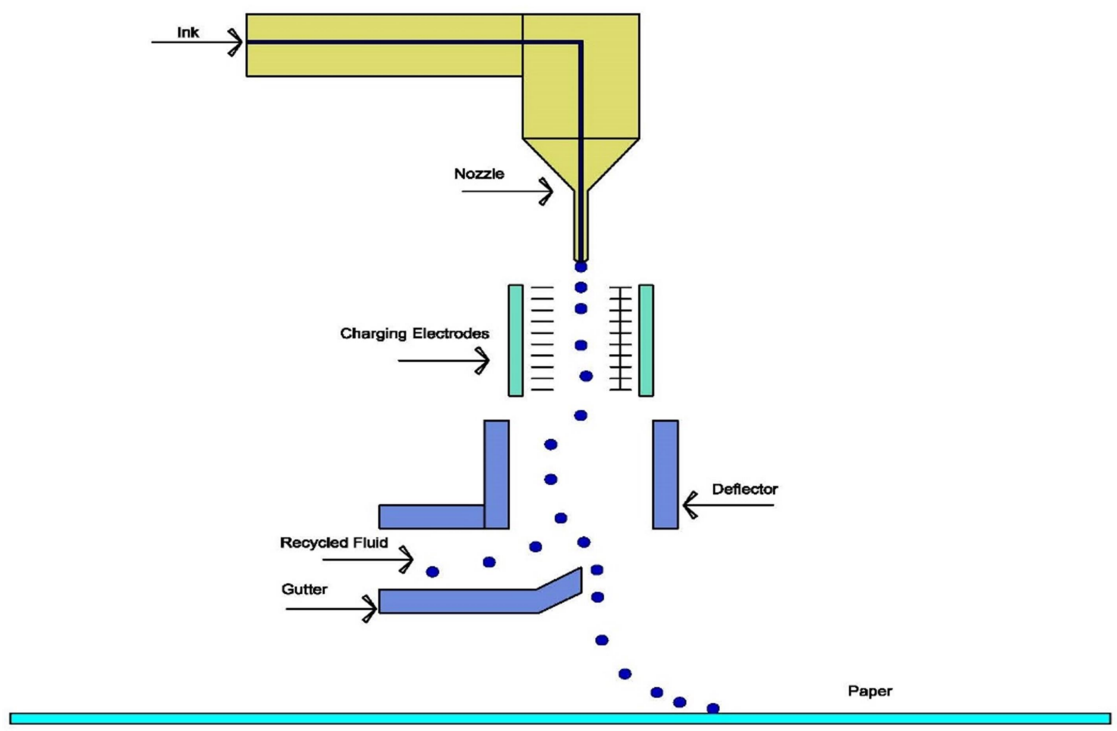

Continuous Inkjet Printing

Figure 1: Schematic diagram depicting continuous inkjet printing

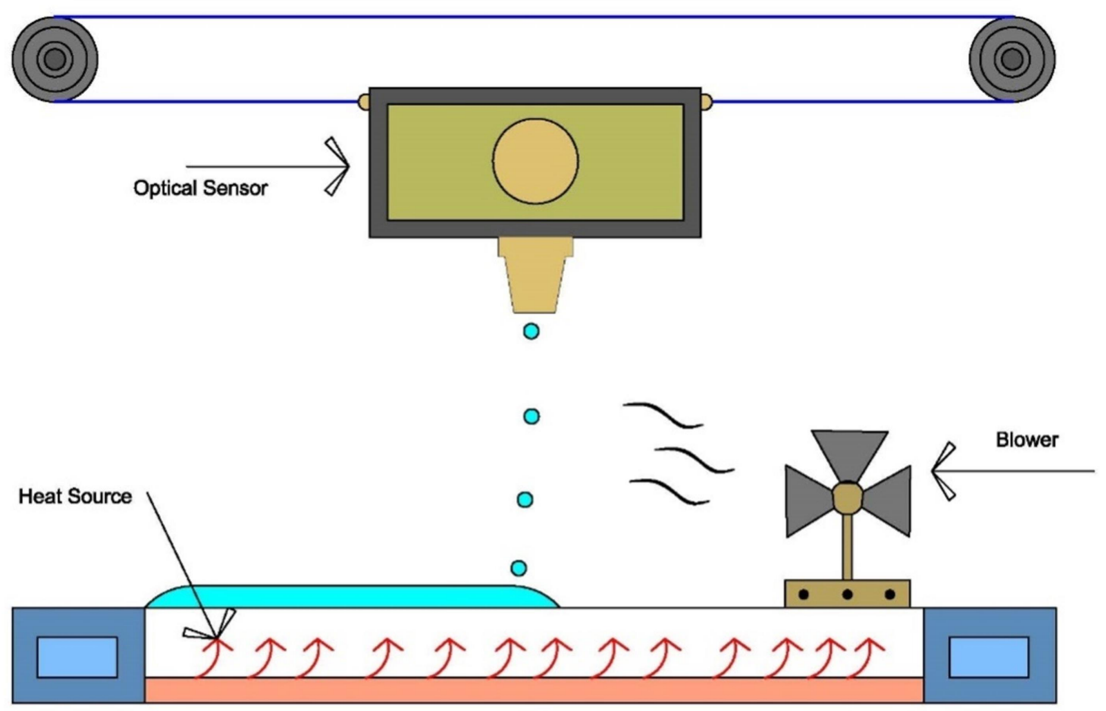

\section{Drop-on-Drop (DOD) deposition}

Figure 2: Schematic diagram depicting Drop-On-Drop (DOD) Deposition 

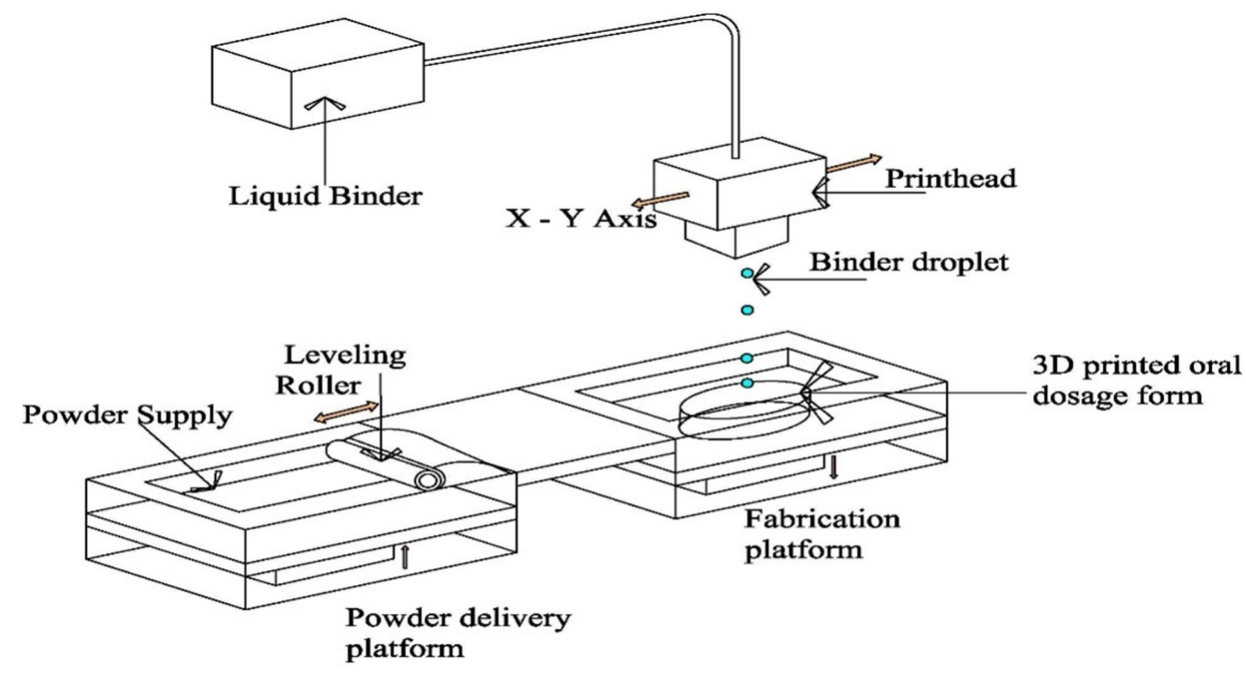

\section{Drop on Solid Deposition}

Figure 3: Schematic diagram depicting Drop-On-Solid (DOS) Deposition

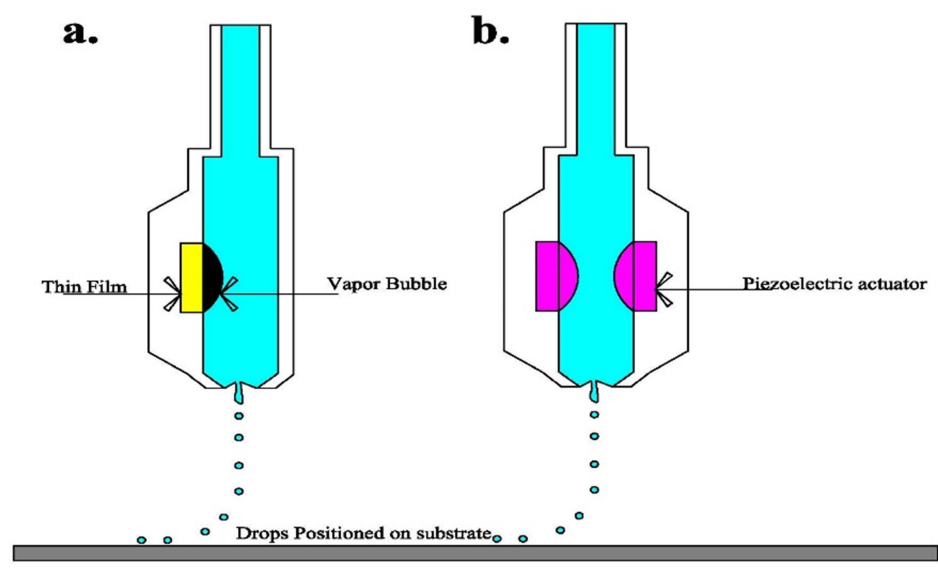
a. Thermal
b. Piezoelectric Print Head Print Head

Figure 4: Schematic diagram depicting Print Heads- a) thermal print head b) piezoelectric print head 


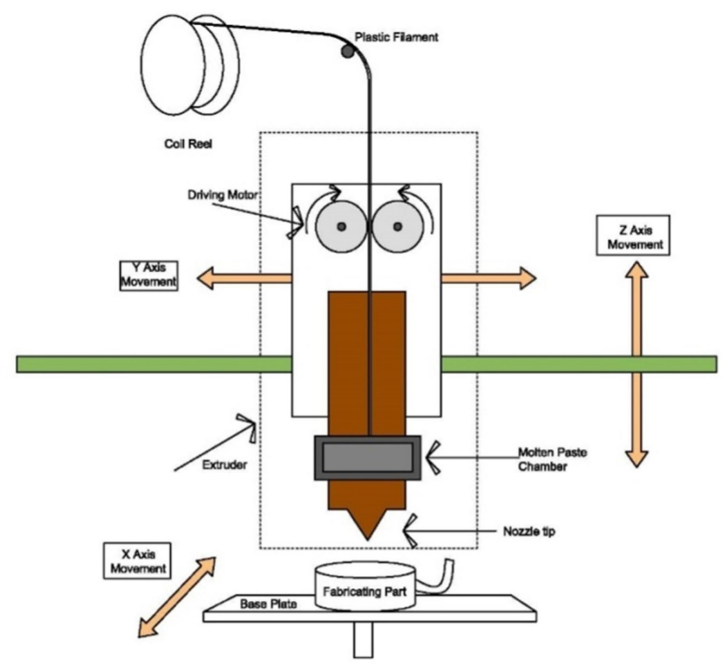

Fused Deposition Modelling (FDM)

Figure 5: Schematic diagram depicting Fused Deposition modelling based 3D printing

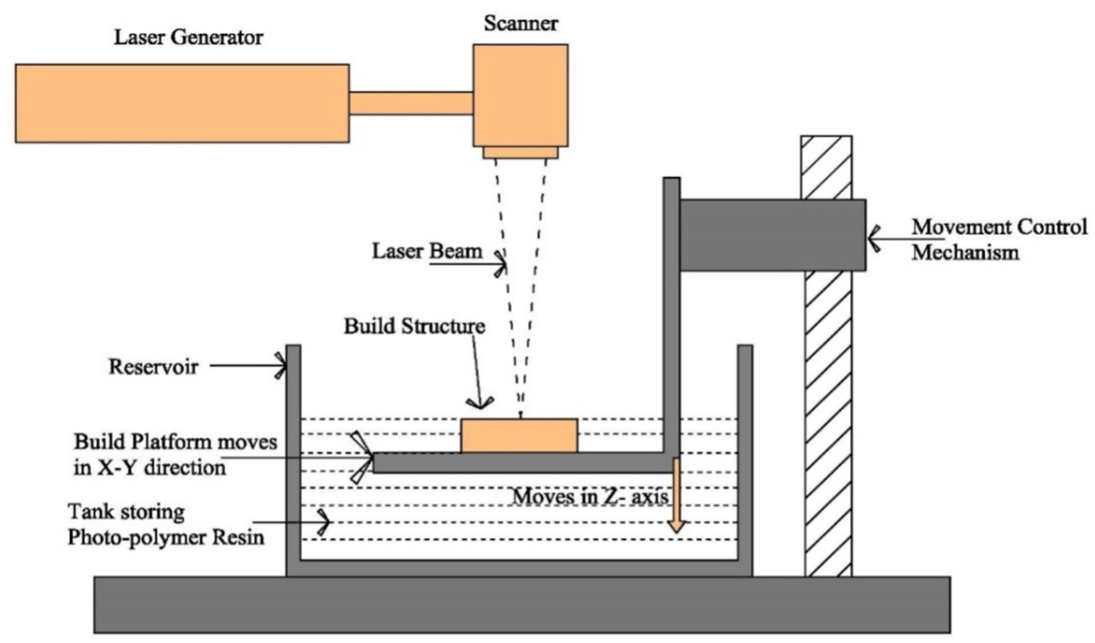

\section{Stereolithography}

Figure 6: Schematic diagram depicting stereolithography (SLA) 


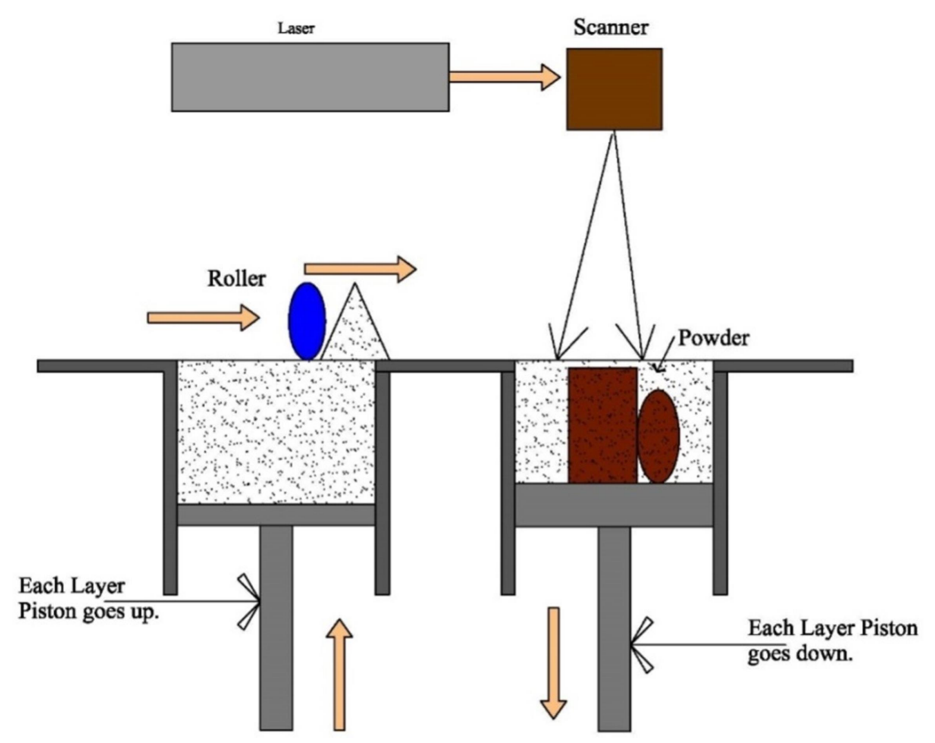

Selective Laser Sintering

Figure 7: Schematic diagram depicting Selective Laser Sintering (SLS)

\section{FUTURE PROSPECTS}

3D printing technology is soon going to replace manufacturing and distribution of drugs by pharmaceutical companies by emailing databases of medication formulations to pharmacies for on-demand drug printing thus reducing the cost of medications. 3D printing technology helps in formulating drugs with narrow therapeutic index and complicated medical devices. Highly innovative products can be manufactured with multimechanism release behavior and combination drug products. $3 \mathrm{D}$ printing opens to new opportunities for formulating novel dosage forms, development of new excipients, multiple drugs incompatibilities can be removed etc. $3 \mathrm{D}$ printing technology is going to remove traditional one fit all type to personalized medication. In future these technology will be proved to be a blessing for development in medical research and medication formulations. Although these technology is now in its budding stage thus it has no such defined laws and regulations and has regulatory burdens yet seeing the advantages of these techniques the hurdles of regulatory process will be overcome and personalized medicines will be dominating the market.

\section{REFERENCES}

[1] Bo YUAN, Sheng-yuan ZHOU, Xiong sheng CHEN. "Rapid prototyping technology and its application in bone tissue engineering", Journal of Zhejiang University Science B Vol. 18, No. 4, pp. 303-315, 2017. 
DOI: 10.1631/jzus.B1600118

[2] NHS. Improving outcomes through personalised medicine 2016. Available at:https://www.fundacionbankinter.org/d ocuments/20183/358137/medicina+perso nalizada-RoGqqCkE.pdf/eedd7a90-d8a44c19-aae9-6764a152fa47

[3] Kianoosh Torabi, Ehsan Farjood, Shahram Hamedani. "Rapid prototypingtechnologies and their applications in prosthodontics, a review of literature", Journal of Dentistry, Vol. 16, No. 1, pp. 1-9, 2015.PMCID: PMC4345107, PMID: 25759851.

[4] Gross BC, Erkal JL, Lockwood SY, Chen C, Spence DM. "Evaluation of 3D printing and its potential impact on biotechnology and the chemical sciences", Analytical Chemistry, Vol. 86, No. 7, pp. 3240-3253,2014. DOI: 10.1021/ac403397r

[5] Rowe CW, Katstra WE, Palazzolo RD, Giritlioglu B, Teung P, Cima MJ. "Multimechanism oral dosage forms fabricated by three dimensional printing (TM)", Journal of Controlled Release, Vol. 66, No. 1, pp. 11-7,2000. DOI: 10.1016/S0168-3659(99)00224-2

[6] Moulton SE, Wallace GG. "3Dimensional (3D) fabricated polymer based drug delivery systems", Journal of Controlled Release, Vol. 193, pp.27-34, 2014. DOI: 10.1016/j.jconrel.2014.07.005

[7] Alomari M, Mohamed FH, Basit AW, Gaisford S. "Personalised dosing: printing a dose of one's own medicine",
Int J Pharm, Vol. 494, pp. 568-577, 2015.

DOI: 10.1016/j.jpharm.2014.12.006

[8] Katstra WE, Palazzolo RD, Rowe CW, Giritlioglu B, Teung P, Cima MJ. "Oral dosage forms fabricated by three dimensional printing", Journal of Controlled Release, Vol. 66, No. 1, pp.19,2000.DOI: 10.1016/S01683659(99)00225-4

[9] Awad A, Trenfield SJ, Goyanes A, Gaisford S, Basit AW. "Reshaping drug development using 3D printing”, Drug Discov Today, Vol.23, No. 8, pp. 15471555, 2018.

DOI:10.1016/j.drudis.2018.05.025

[10] Dimitrov D, Schreve K, de Beer N. "Advances in three dimensional printing-state of the art and future perspectives", Rapid Prototyping Journal, Vol.12, No.3, pp.136-147 2006. DOI:10.1108/13552540610670717

[11] Mathew E, Pitzanti G, Larrañeta E, Lamprou DA. "3D printing of pharmaceuticals and drug delivery devices", Pharmaceutics, Vol. 12, No. 3, pp. 266, 2020.

DOI:10.3390/pharmaceutics12030266

[12] Strutt JW, Rayleigh L. "On the instability of jets", Proc Lond Math Soc, Vol. 10, pp. 4-13 1878. DOI:10.1112/plms/s1-10.1.4

[13] Kuang M., Wang L., Song Y."Controllable Printing Droplets for High-Resolution Patterns", Adv. Matter., Vol. 26, No. 40, pp. 6950-6958, 2014. DOI:10.1002/adma.201305416 
[14] Jonathan G, Karim A. 2016. "3D printing in pharmaceutics: a new tool for designing customized drug delivery systems", Int J Pharm., Vol. 499, No. 1(2), pp. 376-394, 2016. DOI: 10.1016/j.ijpharm.2015.12.071

[15] Calvert P."Inkjet printing for materials and devices", Chem. Mater., Vol. 13, No. 10, pp. 3299-3305, 2001.

DOI: $10.1021 / \mathrm{cm} 0101632$

[16] Yun Y.H., Kim J.D., Lee B.K., Cho Y.W., Lee H.Y. "Polymer Inkjet Printing: Construction of ThreeDimensional Structures at Micro-Scale by Repeated Lamination", Macromol.

Res., Vol. 17, pp. 197202,2009.DOI:10.1007/BF03218679

[17] Rowe CW, Wang CC, Monkhouse DC. "TheriForm technology". In: Rathbone, Hadgraft, Roberts, editors. Modifiedrelease drug delivery technology, 2002, PP. 77-88.

[18] Aulton ME. “Granulation" in Aulton's pharmaceutics: the design and manufacture of medicines. $5^{\text {th }}$ ed., Edinburgh, New York: Churchill Livingstone/Elsevier, 2018, pp. 476-497.

[19] Kipphan H. (Ed.), "Printing Technologies with Permanent Printing Master" in Handbook of print media: Technologies and production methods, Berlin, Germany: Springer,2001, pp. 203-448.

[20] Cooley PW, Wallace DB, Antohe BV. "Applications of ink-jet printing technology to BioMEMS and microfluidic systems", Journal of the
Association for laboratory automation Vol.7, No. 5, pp. 33-39, 2002.

DOI: 10.1016/S1535-5535-04-00214-X

[21] Ge Z., Tian X., Heng B.C., Fan V., Yeo J.F., Cao T. "Histological evaluation of osteogenesis of 3D-printed poly-lacticco-glycolic acid (PLGA) scaffolds in a rabbit model", Biomed. Mater. Vol. 4, No.2, pp. 021001, 2009.

DOI:10.1088/1748-6041/4/2/021001

[22] Khaled SA, Burley JC, Alexander MR, Yang J, Roberts CJ. "3D printing of tablets containing multiple drugs with defined release profiles", Int $\mathrm{J}$ Pharm.Vol. 494, No. 2, pp. 643-650, 2015.

DOI: org/10.1016/j.ijpharm.2015.07.067

[23] Korpela J., Kokkari A., Korhonen H., Malin M., Närhi T., Seppäla J. "Biodegradable and bioactive porous scaffold structures prepared using fused deposition modelling”, Journal of Biomedical Materials Research Part B: Applied Biomaterials, Vol. 101B, No. 4, pp. 610-619, 2012.

DOI: $10.1002 / j b m . b .32863$

[24] Prasad LK, Smyth H. "3D printing technologies for drug delivery: a review”, Drug Dev Ind Pharm., Vol. 42, No. 7, pp.1019-1031, 2016. DOI:10.3109/03639045.2015.1120743

[25] Melchels FP, Feijen J, Grijpma DW. "A review on stereolithography and its applications in biomedical engineering", Biomaterials, Vol. 31, No. 24, pp. 61216130, 2010.

DOI: 10.1016/j.biomaterials.2010.04.050 
[26] Scoutaris N, Alexander M, Gellert $\mathrm{P}$, Roberts C. "Inkjet printing as a novel medicine formulation technique", Journal of Controlled Release, Vol. 156, No. 2, pp. 179-185, 2011.DOI: 10.1016/j.jconrel.2011.07.033

[27] Ross S, Scoutaris N, Lamprou D, Mallinson D, Douroumis D. "Inkjet printing of insulin microneedles for transdermal delivery", Drug Delivery and Translational Research, Vol. 5, No.

4, pp. 451-461, 2015.DOI: 10.1007/s13346-015-0251-1

[28] Uddin MJ, Scoutaris N, Klepetsanis P, Chowdhry B, Prausnitz MR, Douroumis D. "Inkjet printing of transdermal microneedles for the delivery of anticancer agents", International Journal of Pharmaceutics, Vol. 494, No. 2, pp.593-602, 2015.

DOI:10.1016/j.ijpharm.2015.01.038

[29] Lee BK, Yun YH, Choi JS, Choi YC, Kim JD, Cho YW. "Fabrication of drugloaded polymer microparticles with arbitrary geometries using a piezoelectric inkjet printing system", International Journal of Pharmaceutics, Vol. 427, No. 2, pp. 305-310,2012. DOI: 10.1016/j.ijpharm.2012.02.011

[30] Genina N., Fors D., Palo M., Peltonen J. and Sandler N. "Behavior of printable formulations of loperamide and caffeine on different substrates - Effect of print density in inkjet printing", International Journal of Pharmaceutics, Vol. 453, No.2, pp. 488-497, 2013. DOI: 10.1016/j.ijpharm.2013.06.003
[31] Sandler N, Maattanen A, Ihalainen P, Kronberg L, Meierjohann A, Viitala T, et al. "Inkjet printing of drug substances and use of porous substrates towards individualized dosing", Journal of Pharmaceutical Sciences, Vol. 100, No. 8, pp. 3386-3395, 2011. DOI:10.1002/jps.22526

[32] Alomari M, Mohamed F, Basit A, Gaisford S. "Personalised dosing: Printing a dose of one's own medicine", International Journal of Pharmaceutics, Vol. 494, No. 2, pp. 568-577, 2015. DOI: 10.1016/j.ijpharm.2014.12.006

[33] Allen. E, O’Mahony C., Cronin M., O’Mahony .T, Moore .A.C, Crean A.M. "Dissolvable microneedle fabrication using piezoelectric dispensing technology", International Journal of Pharmaceutics, Vol. 500, No. 1(2), pp. 110 , 2016.DOI:

10.1016/j.ijpharm.2015.12.052

[34] Boehm RD, Daniels J, Stafslien S, Nasir A, Lefebvre J, Narayan RJ. "Polyglycolic acid microneedles modified with inkjet-deposited antifungal coatings", Biointerphases, Vol. 10, No. 1, pp. 011004, 2015. DOI: $10.1116 / 1.4913378$

[35] Raijada D, Genina N, Fors D, Wisaeus E, Peltonen J, Rantanen J, et al. "A Step Toward Development of Printable Dosage Forms for Poorly Soluble Drugs", Journal of Pharmaceutical Sciences, Vol. 102, No.10, pp. 36943704, 2013. DOI: 10.1002/jps.23678 
[36] Montenegro-Nicolini, V. Miranda, JO. Morales, "Inkjet Printing of Proteins: an Experimental Approach", Journal of The American Association of Pharmaceutical Scientists, Vol 19, No. 1, pp. 234-243, 2017.DOI: $10.1208 /$ s12248-016-9997-8

[37] K. Boven, S. Stryker, J. Knight, A. Thomas, M.V. Regenmortel, D.M. Kemeny, et al. "The increased incidence of pure red cell aplasia with an Eprex formulation in uncoated rubber stoppersyringes", Kidney International, Vol. 67, No. 6, pp. 2346-2353, 2005.

DOI: $10.1111 / \mathrm{j} .1523-1755.2005 .00340 . \mathrm{x}$

[38] Gu. Y., Chen. X., Lee. J.H., Monteiro. D.A., Wang. H., Lee. W.Y. "Inkjet printed antibiotic- and calcium-eluting bioresorbable nanocomposite micropatterns for orthopedic implants", Acta Biomaterialia, Vol. 8, No. 1, pp. 424-431, 2012.

DOI: 10.1016/j.actbio.2011.08.006

[39] Huang W, Zheng Q, Sun W, Xu H, Yang X. "Levofloxacin implants with predefined microstructure fabricated by three dimensional printing technique", International Journal of Pharmaceutics, Vol. 339, No. 1(2), pp. 33-38, 2007.

DOI: 10.1016/j.ijpharm.2007.02.021

[40] Pardeike J, Strohmeier DM, Schrodl N, Voura C, Gruber M, Khinast J.G., et al. "Nanosuspensions as advanced printing ink for accurate dosing of poorly soluble drugs in personalized medicines", International Journal of Pharmaceutics, Vol. 420, No. 1, pp. 93-100, 2011. DOI: 10.1016/j.ijpharm.2011.08.033
[41] Daly R, Harrington TS, Martin GD, Hutchings IM. "Inkjet printing for pharmaceutics - A review of research and manufacturing”, International Journal of Pharmaceutics, Vol. 494, No. 2, pp. 554-567, 2015.DOI: 10.1016/j.ijpharm.2015.03.017

[42] Tarcha PJ, Verlee D, Hui HW, Setesak J, Antohe B, Radulescu D, et al. "The application of ink-jet technology for the coating and loading of drug-eluting stents", Annals of Biomedical Engineering, Vol. 35, No. 10, pp. 17911799, 2007.DOI: 10.1007/s10439-0079354-2

[43] Marizza. P., Keller. S.S., Mullertz. A., Boisen. A. "Polymer filled microcontainers for oral delivery loaded using supercritical impregnation", Journal of Controlled Release, Vol. 173, pp. 1-9, 2014.

DOI: 10.1016/j.jconrel.2013.09.022

[44] Genina. N; Jansen. E M; Breitenbach. A, Breitkreutz .J, Sandler. N. "Evaluation of different substrates for inkjet printing of rasagiline mesylate", European journal of pharmaceutics and biopharmaceutics, Vol. 85, No. 3, pp. 1075-1083, 2013.DOI: 10.1016/j.ejpb.2013.03.017

[45] Chai. X, Chai. H, Wang. X, Yang. J, Li.J, Zhao. Y, et.al. "Fused Deposition Modeling (FDM) 3D Printed Tablets for Intragastric Floating Delivery of Domperidone", National Center for Biotechnology Information, Vol. 7, pp. 2829,2017.DOI: $\quad$ 10.1038/s41598-01703097-x 
[46] Yan Yang, Huihui Wang, Haichao Li, ZhiminOu, Gensheng Yang. "3D printed tablets with internal scaffold structure using ethyl cellulose to achieve sustained ibuprofen release", Journal of Pharmaceutical Sciences, Vol. 115, pp. 11-18, 2018.2 DOI: 10.1016/j.ejps.2018.01.005

[47] Alvaro Goyanes , Asma B.M. Buanz , GraceB. Hatton, Simon Gaisford, Abdul W. Basit. "3D printing of modifiedrelease aminosalicylate (4-ASA and 5ASA) tablets", European Journal of Pharmaceutics and Biopharmaceutics, Vol. 89, pp. 157-162, 2015. DOI: 10.1016/j.ejpb.2014.12.003

[48] Christos I. Gioumouxouzis, Apostolos Baklavaridis , Orestis L. Katsamenis , Catherine K. Markopoulou, Nikolaos Bouropoulos, Dimitrios Tzetzis, et al. "A 3D printed bilayer oral solid dosage form combining metformin for prolonged and glimepiride for immediate drug delivery", European Journal of Pharmaceutical Sciences, Vol. 120, pp. 40-52,2018.DOI:

10.1016/j.ejps.2018.04.020

[49] Tochukwu C. Okwuosa, Dominika Stefaniak, Basel Arafat, Abdullah Isreb, Ka-Wai Wan, Mohamed A. Alhnan. “A Lower Temperature FDM 3D Printing for the Manufacture of Patient-Specific Immediate Release Tablets", Pharmaceutical Research, Vol. 33, No. 11, pp. 2704-2712, 2016. DOI:10.1007/s11095-016-1995-0
[50] Alvaro Goyanes , Fabrizio Fina , Annalisa Martorana, Daniel Sedough , Simon Gaisford, Abdul W. Basit. "Development of modified release 3D printed tablets (printlets) with pharmaceutical excipients using additive manufacturing", International Journal of Pharmaceutics, Vol. 527, No.1(2), pp. 21-30, 2017.DOI: 10.1016/j.ijpharm.2017.05.021

[51] Tochukwu C. Okwuosa, Beatriz C. Pereira, Basel Arafat, Milena Cieszynska, Abdullah Isreb. Mohamed A. Alhnan. "Fabricating a Shell-Core Delayed Release Tablet Using Dual FDM 3D Printing for Patient-Centred Therapy", Pharmaceutical Research, Vol. 34, No. 2, pp. 427-437, 2017.DOI: 10.1007/s11095-016-2073-3

[52] Justyna Skowyra , Katarzyna Pietrzak , Mohamed A. Alhnan. "Fabrication of extended-release patient-tailored prednisolone tablets via fused deposition modelling (FDM) 3D printing", European Journal of Pharmaceutical Sciences, Vol. 68, pp.11-17 2015. DOI: 10.1016/j.ejps.2014.11.009

[53] MuznaSadia, Abdullah Isreb, Ibrahim Abbadi, Mohammad Isreb , David Aziz, Amjad Selo, et al. "From 'fixed dose combinations' to 'a dynamic dose combiner': 3D printed bi-layer antihypertensive tablets", European Journal of Pharmaceutical Sciences, Vol. 123, pp. 484-494, 2018. DOI: 10.1016/j.ejps.2018.07.045 
[54] Furqan A Maulvi, Manthal J Shah, Bosky S Solanki, Akanksha S Patel, Tejal G Soni, Dinesh O Shah. "Application of 3D printing technology in the development of novel drug delivery systems", International journal of drug development and research, Vol. 9, pp. 44-49, 2017. ISSN: 0975-9344.

[55] Sandler N, Salmela I, Fallarero A, Rosling A, Khajeheian M, Kolakovic R, et al. "Towards fabrication of $3 \mathrm{D}$ printed medical devices to prevent biofilm formation", International Journal of Pharmaceutics, Vol. 459, No. 1(2), pp. 62-64, 2014.2 DOI: 10.1016/j.ijpharm.2013.11.001

[56] Masood SH. "Application of fused deposition modelling in controlled drug delivery devices", Assembly Automation, Vol. 27, No. 3, pp. 215221, 2007.

DOI: $10.1108 / 01445150710763231$

[57] Weisman JA, Nicholson JC, Tappa K, Jammalamadaka U, Wilson CG, Mills DK. "Antibiotic and chemotherapeutic enhanced three-dimensional printer filaments and constructs for biomedical applications", International Journal of Nanomedicine, Vol. 10, pp. 357-370, 2015. DOI: 10.2147/IJN.S74811

[58] Melocchi A, Parietti F, Loreti G, Maroni A, Gazzaniga A, Zema L. "3D printing by fused deposition modeling (FDM) of a swellable/erodible capsular device for oral pulsatile release of drugs", Journal of Drug Delivery Science and Technology, Vol. 30 Part B, pp. 360-
367 , 2015.

DOI:

10.1016/j.jddst.2015.07.016.

[59] Khaled SA, Burley JC, Alexander MR, Yang J, Roberts CJ. "3D printing of five-in-one dose combination polypill with defined immediate and sustained release profiles". Journal of Controlled Release, Vol. 217, pp. 308-314, 2015. DOI: $10.1016 /$ j.jconrel.2015.09.028

[60] Goyanes A, Buanz AB, Basit AW, Gaisford S. "Fused-filament 3D printing (3DP) for fabrication of tablets", International Journal of Pharmaceutics, Vol. 476, No. 1(2), pp. 88-92, 2014. DOI: 10.1016/j.ijpharm.2014.09.044

[61] Genina N, Hollander J, Jukarainen H, Makila E, Salonen J, Sandler N. “ Ethylene vinyl acetate (EVA) as a new drug carrier for 3D printed medical drug delivery devices", European Journal of Pharmaceutical Sciences, Vol. 90, pp. 53-63, 2016.

DOI: 10.1016/j.ejps.2015.11.005

[62] Sadia M, Sośnicka A, Arafat B, Isreb A, Ahmed W, Kelarakis A, et al. "Adaptation of pharmaceutical excipients to FDM 3D printing for the fabrication of patient-tailored immediate release tablets, International journal of Pharmaceutics, Vol. 513, No. 1(2), pp. 659-668, 2016.

DOI: 10.1016/j.ijpharm.2016.09.050

[63] Jie Wang, Alvaro Goyanes, Simon Gaisford, Abdul W. Basit. "Stereolithographic (SLA) 3D printing of oral modified-release dosage forms", International journal of pharmaceutics, 
Vol. 503, No. 1(2), pp. 207-212, 2016.

DOI: 10.1016/j.ijpharm.2016.03.016

[64] Goyanes A, Det-Amornrat U, Wang J, Basit AW, Gaisford S. "3D scanning and 3D printing as innovative technologies for fabricating personalized topical drug delivery systems", Journal of Controlled Release, Vol. 234, pp. 41-48, 2016. DOI: 10.1016/j.jconrel.2016.05.034 